\title{
LENGUAJE AUDIOVISUAL Y EXPERIENCIA MÍSTICA EN LA NOCHE OSCURA, DE CARLOS SAURA
}

\author{
Mariona Visa Barbosa: Universitat Pompeu Fabra (España)
}

\section{Introducción}

Este artículo tiene como propósito analizar la utilidad del lenguaje audiovisual para transmitir la experiencia mística. No desde el punto de vista testimonial, dónde el autor de la película intenta narrar una experiencia mística propia, sino para ilustrar la experiencia vivida por los místicos anteriores. En este caso, para observar y analizar los recursos audiovisuales y estilísticos que Carlos Saura utilizó en La noche oscura (1989) a la hora de transmitir la experiencia que San Juan de la Cruz vivió durante los nueve meses de reclutamiento en la prisión de Toledo.

San Juan de la Cruz, junto con otros místicos, manifestó siempre la "inefabilidad" del lenguaje para transmitir su experiencia. Mi objetivo en este artículo es ver si el lenguaje audiovisual puede ir más allá que la palabra, si es por si sólo más potente, o simplemente es el complemento perfecto. Y cuáles son sus límites.

San Juan de la Cruz utiliza en su obra un gran número de recursos lingüísticos para intentar transmitir la experiencia mística. El mismo autor dijo que no encontraba las palabras para explicar todo aquello que se siente en contacto con la divinidad. Utiliza un lenguaje ambiguo y a menudo contradictorio, insistiendo siempre en la inefabilidad, en la imposibilidad de transmitir en un lenguaje codificado su experiencia al resto de la población. Expresiones populares, palabras del mundo de la naturaleza, palabras cultas latinizadas, oxímorons, símbolos, alegorías... Los místicos generan un lenguaje nuevo a partir de lo que Jean Baruzzil define como "transmutaciones" operadas en el interior de vocablos surgidos del lenguaje normal. Como dice López Barralt, "la lucha sin cuartel con el lenguaje humano, que parecería se le quema entre las manos y se le queda siempre corto"1. Maria Jesús Mancho $^{2}$ ha realizado un análisis del lenguaje utilizado por San Juan de la Cruz en sus poemas. En su estudio afirma que el poeta utiliza un gran número de tecnicismos a partir de la sufijación (arrobamiento, absorbimiento), términos prestados de disciplinas afines o cultismos. $\mathrm{Y}$ también, el uso de las metáforas amorosas como "matrimonio espiritual", "amada" y "esposo" para representar la unión entre el alma y Dios.

\footnotetext{
${ }^{1}$ López Barralt. Asedios a lo indecible. Ed. Trotta. Madrid. 1998

${ }^{2}$ La experiència mística. Estudio interdisciplinar. Edición de Juan Martín Velasco. Ayuntamiento de Ávila. Ed. Trotta. 2004 Pág.219
} 
Esta inefabilidad viene dada por diversos factores. Uno de ellos es el hecho que la experiencia mística se vive en carne propia, no es un conocimiento que venga dado por las opiniones de terceros. Se trata de explicar una vivencia que se ha sufrido en primera persona y que ha llevado los propios sentidos al éxtasis. La mística es una forma especial de conocimiento de Dios que se caracteriza por su condición de experiencia y por llegar a Dios más allá de lo que permiten conseguir el conocimiento que los otros explican de él. ¿Cómo expresar la experiencia de haber entrado en contacto con un más allá, con una realidad completamente nueva?

El Santo se vio obligado, a su pesar, a escribir unos comentarios a sus poemas, dónde intenta explicar a través de la prosa aquello que el lenguaje poético podía llevar a equívocos. "porque son tantas y tan profundas las tinieblas y trabajos, así espirituales como temporales, por que ordinariamente suelen pasar las dichosas almas para poder llegar a este alto estado de perfección, que ni basta ciencia humana para lo saber entender, ni experiencia para lo saber decir,; porque sólo el que por ello pasa sabrá sentir, mas no decir' ${ }^{3}$, dice San Juan en el prólogo a la Subida al Monte Carmelo.

Empezamos, por tanto, a analizar los recursos propios del lenguaje audiovisual, obviamente no presentes en los escritos de San Juan de la Cruz, para realizar nuestro estudio. A partir de la enumeración de los diferentes recursos visuales y estilísticos utilizados por Carlos Saura, será analizado su significado con relación a la plasmación que éstos hacen de la experiencia mística.

\section{El argumento}

La historia que explica la película se basa en la vida de San Juan de la Cruz durante los nueve meses que estuvo preso en Toledo el año 1577, a causa de haber participado en la reforma de la orden carmelita. Estuvo cerrado en una celda pequeña con una única ventana que le iluminaba durante breves momentos al mediodía. A dieta de prácticamente sólo pan y agua. Los hermanos Descalzos le propinaban palizas para que abjurara de la Reforma. En estas circunstancias la gracia de Dios le inspiró sus primeros versos del Cántico Espiritual.

En la película, San Juan de la Cruz, interpretado por Juan Diego, recita, a parte de los primeros versos del Cántico, el poema de La noche oscura y algunos versos de otros poemas. La noche oscura es el título de uno de los tres poemas más conocidos de San Juan de la Cruz. Pero la utilización de este título no hace referencia a que la película sea la ilustración audiovisual del poema, sino que explica la historia de los nueve meses en que el Santo estuvo preso en Toledo. Durante estos meses se gestaron y memorizaron los tres poemas que escribió después de huir. Igualmente, el Santo se refirió a este período como la "noche oscura", por tanto

\footnotetext{
${ }^{3}$ DE LA CRUZ, San Juan. Obra completa. Alianza editorial. Madrid. 1991.Pág. 114
} 
la referencia es clara. "para que una alma llegue al estado de perfección, ordinariamente ha de pasar primero por dos maneras principales de noches, que los espirituales llaman purgaciones o purificaciones del alma, y aquí las llamamos noches, porque el alma, así en la una como en la otra, camina como de noche, a oscuras."

Este término tiene una lectura literal (el tiempo preso) y también una lectura simbólica (el camino hacia el éxtasis). La noche como privación del gusto en el apetito de todas las cosas. Además el hecho de utilizar la experiencia biográfica, haciendo de la película un biopic, la visión de la obra del Santo es más completa, ya que el texto del poema es complementado con la propia experiencia. Como decía el filosofo Husserl, el estudio de la vida de los santos es dónde se encuentra la experiencia religiosa en estado puro. La experiencia es el núcleo esencial del fenómeno místico.

En la película de Carlos Saura sólo vemos cómo el Santo pasa por la vía purgativa, no por la vía iluminativa o por la noche pasiva. Hace referencia a la noche activa. La otra es más interna, no se visualizaría bien en las imágenes. "el alma entra ordinariamente en esta noche sensitiva en dos maneras: la una es activa; la otra, pasiva". La activa es aquella en que el alma pone de su parte, la pasiva es en la que actúa Dios.

\section{Personajes}

La película sirve también para explicar de forma metafórica lo que San Juan expresa como la "Subida al Monte Carmelo". El Santo explica a su carcelero que ha tenido contacto con el demonio y que pecó cuando en el convento dónde estaba conoció a Ana de Jesús. Esta chica, en la primera parte de la película, encarnará el alma del personaje, que debe purificarse para poder llegar a la unión con Dios. Se muestra cómo sucumbe al pecado de la carne y cómo peca de lujuria. Aparece endemoniada y el propio San Juan trata de exorcizarla. Más tarde, a medida que la luz divina ha iluminado al Santo, el alma se purifica hasta que pasará a encarnar la figura de la Virgen Maria. Será entonces cuando él grita, y se produce la unión entre el alma y el esposo, una vez el alma ya está del todo purificada. Esta puesta en escena es una buena utilización de los personajes para transmitir la unión divina, ya que también en los poemas de San Juan encontramos connotaciones amorosas muy implícitas que hacen que el matrimonio espiritual parezca en algunos momentos la unión sexual de dos amantes. Por tanto, no resulta extraño cuando el alma y el esposo se besan en la boca y se abrazan cuando se encuentran. Para hacerlo factible sin connotaciones homosexuales, en esta escena el alma es San Juan de la Cruz, y el esposo la Virgen Maria en lugar de Dios.

\footnotetext{
${ }^{4}$ DE LA CRUZ, San Juan. Obra completa. Alianza editorial. Madrid. 1991. Pág. 120
} 
Esta fusión de personajes es, por otro lado, muy habitual en adaptaciones audiovisuales de hechos reales, ya que así el espectador entiende los hechos sin tener que recorrer a más personajes. A pesar de todo, creo que en este caso también se buscaba la confusión entre alma y esposo (pecado-purificación, nochedía) que se crea al utilizar la misma actriz (July Delpy) para encarnar los dos roles. El componente erótico y sexual tiene también mucha importancia. Como dice Carlos Domínguez Morano, "si somos capaces de amar a Dios es porque somos seres sexuados, deseantes. Es más, habría incluso que sospechar de una experiencia mística en la que la sexualidad no estuviera de un modo u otro presente". 5

La utilización por parte del director de imágenes fijas que funcionan a modo de naturalezas muertas es también muy interesante. Platos de sardinas, jarrones de agua, racimos de uvas... se hacen presentes en la narración también como protagonistas. Como hacían en el barroco maestros como Zurbarán y Caravaggio. Y como José de Ribera (II Spagnoleto), Carlos Saura escruta los rostros masculinos (San Andrés) con detalle para observar la piel dañada y las piernas esqueléticas. En cambio, muestra las mujeres con exageración de su belleza (en el caso de Santa Inés).

\section{Dirección de fotografía}

En la dirección de fotografía de la película hay una clara influencia del tenebrismo pictórico. El claroscuro, con el fuerte contraste visible entre luces y sombras es la mejor manera de reflejar la figura retórica del oxímoron. La "noche luminosa" del poema pasa a ser una imagen de tiniebla absoluta rota sólo por un único rayo resplandeciente que ilumina la mente del personaje. Se plasma la luz se visualiza, de la misma manera que en las composiciones simples de Caravaggio, dónde la luz provoca fuertes oposiciones entre la zona iluminada y la oscura. En los cuadros del barroco normalmente se plasma con fuerza el movimiento, la turbulencia, las figuras inestables. En este caso predomina la quietud, pero en el barroco, cuando pintaban temas religiosos también predominaba esta austeridad de movimiento para representar la trascendencia religiosa.

El primer movimiento cinematográfico que utilizó la fuerza expresiva fue el expresionismo alemán. Autores como Fritz Lang, Robert Wiene o Murnau aprovecharon la oposición entre luces y sombras para representar la lucha entre el bien y el mal, a menudo una lucha que se libraba dentro de los personajes. Claroscuros, rayos contrastados, sombras, todos estos elementos iban acompañados en el expresionismo también de desproporciones geométricas, pero tienen nexos de unión con la obra de Carlos Saura. La utilización de la luz como

\footnotetext{
${ }^{5}$ La experiència mística. Estudio interdisciplinar. Edición de Juan Martín Velasco. Ayuntamiento de Ávila. Ed. Trotta. 2004 P.216
} 
personaje y la movilidad de está por el cuerpo del Santo hasta llegar a su mente para inspirarle los poemas, son ejemplo de esta influencia.

\section{Visiones}

Otro de los recursos utilizados por Carlos Saura son las visiones del protagonista. En su delirio, el Santo ve la representación del alma, en este caso encarnada por una mujer. De esta manera, la diferenciación entre el alma y el esposo (el yo y Dios) hecha por el místico encuentra su encarnación con la mujer como alma y el esposo como rayo luminoso. Hay un momento en que se le aparece el alma ya purificada, ahora representando a la Virgen María, y le dice: “iDebéis marcharos?". Se trata de una visión gótica, con cirios alrededor de la virgen, y el Santo hará exactamente aquello que ella le dice. Pero San Juan, en su obra, avisa al lector que debe de tener cuidado con las visiones, las frases premonitorias o las revelaciones que pueda escuchar, ya que Dios se manifiesta sólo por él mismo, sin ningún disfraz. "Por tanto, para venir a esta unión de amor de Dios esencial, ha de tener cuidado el alma de no ser ir arrimando a visiones imaginarias, ni formas, ni figuras, ni particulares inteligencias, pues no le pueden servir de medio proporcionado y próximo para tal efecto; antes le harían estorbo, y por eso las ha de renunciar y procurar de no tenerlas". 6

\section{Las transiciones}

Las transiciones que utiliza el director más a menudo son los fundidos a negro. Estos fundidos son normalmente utilizados en el cine para indicar un paso de tiempo largo, o para indicar el fin de la película. En La noche oscura son muy utilizados a pesar que el tiempo diegético es de unos nueve meses, un tiempo que no es excesivo si tenemos en cuenta que una película acostumbra a explicar períodos de tiempo mucho más largos, con elipsis que suponen saltos de tiempo muy extensos. La noche oscura esta explicada en orden cronológico, sin ningún desorden en la narración de la historia. Los fundidos, por tanto, sirven aquí como transiciones que indican el paso del tiempo de unos días o de unas semanas. Para este tipo de salto no haría falta utilizar el fundido, pero el hecho que el director lo haya escogido como transición principal produce una sensación de días que nunca terminan, de tiempo reducido pero considerado eterno. Incluso también remite a la idea de repetición, ya que el espectador asocia los fundidos a saltos de tiempo muy largos, dónde se acostumbra a producir un cambio importante en la vida de los personajes (de niño a adulto, del presente al pasado....). Aquí, en cambio, los días se suceden pero la escena continua siendo la misma, la posición del Santo idéntica y también sus obsesiones. En algunos casos, estos fundidos van acompañados de rótulos indicativos del mes del año. Así, el espectador se puede situar, ya que sin este referente temporal seria muy difícil saber exactamente qué período de tiempo cubre la película.

\footnotetext{
${ }^{6}$ DE LA CRUZ, San Juan. Obra completa. Alianza editorial. Madrid. 1991. Pág. 228
} 
La concepción del tiempo es muy interesante porque Carlos Saura hace coincidir las estaciones con los estados de ánimo de San Juan. De esta manera, los momentos de tentación son mostrados durante el invierno, mientras que la emancipación espiritual se da durante la primavera.

\section{Símbolos}

La utilización de los símbolos es también muy importante. Una de las características del lenguaje místico es su condición simbólica. La noche, el alma, la desnudez, el rayo luminoso (como divinidad), el color negro como la ausencia de luz... Según López Barralt, la noche es símbolo del transito que hace el alma hasta Dios, de la privación del gusto para las cosas mundanas. La noche es un proceso básico de la experiencia mística, ya que comprende el período de duda y de tentación antes de la ascensión. Edith Stein dice que en la noche en San Juan de la Cruz es "algo informe e inaprensible que, en la plenitud de su sentido, sólo sugiere sin agotar nunca su contenido. En ello se incluye una cosmovisión completa y una perfecta concepción del ser" ${ }^{\prime 7}$. En la película vemos como el alma, representada por la mujer, pasa de ser un ser terrenal, sumergido en los pecados de la carne, a elevarse hasta conseguir el contacto con Dios.

En una noche oscura,

Con ansias en amores inflamada,

¡oh dichosa ventura!

Salí sin ser notada,

Estando ya mi casa sosegada.

En los poemas, el sujeto de las canciones es esta alma una vez ya se ha levantado de la carne. Para que el alma pueda volar debe haber un recogimiento de las pasiones, para que Dios pueda nacer en el alma, ésta debe de ser pura, virgen. Debe desprenderse de todas las pasiones carnales, del cinismo. "La casa que ha dejado la esposa es la parte sensible del alma. Está sosegada porque todos sus apetitos han sido acallados." 8 "Este desprendimiento deja el alma en tinieblas y como sin nada. Por esta razón se la denomina noche." La ascensión del hombre hacia Dios es un proceso en el que debe haber un vacío para poder llegar a la plenitud de Dios.

El rayo luminoso es también un símbolo, que significa como la divinidad se hace presente y toca al Santo interiormente. Según el Santo, el autor de sus versos era Dios, que le inspiraba el texto que él iba transcribiendo. Por tanto, el símbolo del rayo que ilumina al Santo es utilizado para representar esta inspiración divina. Una

\footnotetext{
${ }^{7}$ STEIN, Edith. Ciencia de la cruz. Ed. Monte Carmelo. Burgos Pág. 52

${ }^{8}$ STEIN. Edith. Ciencia de la cruz. Ed. Monte Carmelo. Burgos Pág. 55
} 
vez se ha producido este proceso, dónde la luz recorre todo su cuerpo, el Santo no puede dejar de exclamar: “Qué hermoso!”. María Jesús Fernández Leborans en su estudio sobre las connotaciones del semema luz, vincula éste a los términos Dios, Cristo y Saber: "La luz permite a la potencia visual humana distinguir los objetos físico-materiales porque los "aclara" (los pone claros, los esclarece), haciendo visibles su forma, tamaño, límites, color, etc...; de modo análogo, la sabiduría o ilustración de Dios permite a las potencias del alma la capacidad de distinguir, dilucidar, lo que es sobrenatural de lo que no lo es, y por revelación, implica, además, la capacidad de aprehensión de verdades relativas a lo trascendente". ${ }^{9}$ Por otro lado, la palabra oscuridad connota otro tipo de vocablos como: noche, tinieblas, pecado, frío, prisión, ceguera, ignorancia...

Otro de los símbolos en la película es la ventana. A lo largo del filme permite la entrada del rayo luminoso que ilumina e inspira al Santo. Al final, cuando una ventana del pasillo queda abierta representa el mundo exterior. Jordi Balló, en su libro Imatges del silenci habla de este símbolo y de sus efectos, ya que es un elemento que marca claramente los paisajes entre el interior y el exterior. "La ventana evoca el sueño porque nos permite ver lejos, ver otras cosas. El carácter inamovible del paisaje convierte el fondo en un tapiz neutral, en un continuum que es metáfora de la vida repetitiva. Es a través de la ventana que se manifiesta la aspiración romántica del superamiento."10

"El fuera de campo remite a lo que no se oye ni se ve, y sin embargo está perfectamente presente."11 En este caso, el fuera de campo es el paisaje que queda más allá de aquellos muros, pero a la vez alude a todo el futuro que tiene el Santo por delante, toda la obra que le queda por componer.

La sombra del Santo es vista como símbolo de humanidad, de carne. En el análisis de la pintura de la Enunciación de Filippo Lippi, Stoichita afirma que la proyección de la sombra del ángel Gabriel es un signo múltiple, ya que demuestra que el ángel no es una aparición sino una realidad concreta. Igualmente, en la escena de la Epifania en que Cristo es mostrado, el autor concluye que "la sombra evidencia la presencia real de la divinidad que se ha hecho cuerpo"12.

Otra visión muestra al Santo yaciendo en la cama rodeado de manos que le recorren y se arrapan a su cuerpo. Estas manos, símbolo de la tentación, llevan al Santo a confesar a su ayudante que esta no es la primera vez que siente la tentación, que una vez cayó pero que ahora no le vencerá.

\footnotetext{
${ }^{9}$ FERNANDEZ LEBORANS. Luz y oscuridad en la mística española. Cupsa editorial. Madrid Pág. 230.

${ }^{10}$ BALLÓ, Jordi. Imatges del silenci. Ed. Empúries. 2000 Pág. 20

${ }^{11}$ DELEUZE, Gilles. La imagen-movimiento. Paidós Comunicación Pág. 32

${ }^{12}$ STOICHITA, Victor. Breve historia de la sombra. Ed. Siruela. 2000 Pág.88
} 


\section{La realización}

Por lo que respecta a la realización, se opta siempre por planos generales de durada larga. De esta manera, la cadencia de la película es lenta, haciendo más fácil la transmisión de la sensación de quietud y de que los días pasan lentamente.

Los planos generales en el cine se utilizan habitualmente como planos de situación, para que el espectador sepa perfectamente cuál es el contexto de la acción. A menudo también se utilizan cuando en el plano hay muchos elementos diferentes que llaman la atención (muchos personajes o muchos elementos visuales importantes en la acción). Pero aquí los planos generales sirven para mostrar un único personaje estático en un espacio minimalista, que se muestra principalmente en penumbra. Sirve, por tanto, para que el espectador obtenga la sensación de monotonía que tuvo el propio Santo, o para sumergir al espectador en la claustrofobia de estar cerrado en un mismo espacio durante tanto tiempo. Vemos como esta sensación no se consigue con planos cortos, sino desde la distancia, dando al espectador pocos elementos para explorar dentro del plano y manteniendo la misma imagen durante segundos que parecen minutos.

\section{Banda sonora}

No podemos olvidar que una obra audiovisual, a parte de hablar con las imágenes, también se expresa con la banda sonora. Ésta está formada de la palabra, la música, los efectos sonoros y del silencio. La sabia conjunción de estos elementos potencia el efecto de las imágenes, sirviendo como ayuda al propósito del director. La ausencia de diálogo en gran parte de la película es también muy importante. El silencio actúa como vehículo para entrar dentro del personaje. La música, irrumpe en muchos momentos para culminar ya sea el éxtasis o la soledad que vive el protagonista. Por tanto, esta música actúa como revulsivo, transporta al espectador a lugares dónde la imagen sólo deja intuir. Como señala Michel Chion, el sonido tiene una dinámica temporal propia, supone siempre movimiento, al contrario que la imagen: "El sonido implica forzosamente por naturaleza un desplazamiento, siquiera mínimo, una agitación." ${ }^{13}$

\section{Conclusiones}

A través de los recursos estilísticos propios del lenguaje audiovisual como la selección del argumento, la elección de los personajes, la dirección de fotografía, el tratamiento de las visiones, el uso de las transiciones, de los símbolos, la realización y la banda sonora; la película La noche oscura trata de trasladar a la pantalla la experiencia mística que San Juan de la cruz plasmó en su obra escrita.

No se pueden comparar los dos lenguajes y no ha sido ésta la intención del artículo, sino ver la efectividad del lenguaje audiovisual para ilustrar la obra del Santo. Y

\footnotetext{
${ }^{13}$ CHION, Michel. La audiovisión. Paidos ibérica . 1993 Pág. 21
} 
podemos concluir que Carlos Saura ha plasmado la experiencia mística de forma notable, utilizando de la mejor manera posible los recursos que un cineasta tiene a su alcance. Además, de forma meditada y contenida ya que a pesar de la riqueza en metáforas y de la influencia del tenebrismo, la totalidad de la película destaca por su austeridad, característica que se refleja también en la obra y la doctrina del Santo.

\section{Referencias}

La Experiencia Mística. Estudio Interdisciplinar. Edición De Juan Martín Velasco. Ayuntamiento De Ávila. Ed. Trotta. 2004

BALLÓ, Jordi. Imatges Del Silenci. Ed. Empúries. Barcelona. 2000

CHION, Michel. La Audiovisión. Paidos Ibérica. Madrid. 1993

DE LA CRUZ, San Juan. Poesías. Clásicos Castalia. Madrid.

DE LA CRUZ, San Juan. Obra Completa. Alianza Editorial. Madrid. 1991.

DELEUZE, Gilles. La Imagen-Movimiento. Paidós Comunicación.

DELEUZE, Gilles. La Imagen-Tiempo. Paidós Comunicación.

D'LUGO, Marvin. The Films Of Carlos Saura. The Practice Of Seeing. Princeton University Press. 1991

FERNÁNDEZ Leborans, María Jesús. Luz Y Oscuridad En La Mística Española. Cupsa Editorial. Madrid

STEIN, Edith. Ciencia De La Cruz. Ed. Monte Carmelo. Burgos.

STOICHITA, Víctor. Breve Historia De La Sombra. Ed. Siruela. 2000 